\title{
Development of Smart Waste Bin for Solid Waste Management
}

\author{
Sunday A. Afolalu ${ }^{1}$, Ayodeji A. Noiki², Omolayo M. Ikumapayi ${ }^{1 *}$, Adebayo T. Ogundipe ${ }^{3}$, Olamilekan R. Oloyede ${ }^{1}$ \\ ${ }^{1}$ Department of Mechanical and Mechatronics Engineering, Afe Babalola University, Ado Ekiti 360101, Nigeria \\ ${ }^{2}$ Department of Mechanical Engineering Technology, Ogun State Institute of Technology, Igbesa 112212, Nigeria \\ ${ }^{3}$ Directorate of information Communication Technology, Afe Babalola University, Ado Ekiti 360101, Nigeria
}

Corresponding Author Email: ikumapayi.omolayo@abuad.edu.ng

https://doi.org/10.18280/ijsdp.160805

Received: 20 May 2021

Accepted: 1 September 2021

\section{Keywords:}

microcontroller, sensor, servo motor, smart, waste management

\begin{abstract}
Growing urbanisation in developing countries, population growth, and changes in human activities and consumption patterns have resulted in significant amounts of trash that must be appropriately disposed of, treated, and managed to provide a sustainable environment and a reasonable standard of life for the growing population. The aim of the paper is to design a smart dustbin for proper disposal of waste without any human intervention by providing a smart technology for waste system monitoring, reducing human time, effort, and intervention. This paper presents a smart waste bin integrated with a microcontroller-based Arduino board which is interfaced with ultrasonic sensors, MQ-2 sensor, servo motor, LCD and GSM modem. The Arduino microcontroller is programmed using Arduino $\mathrm{C}$ which measures the height of the dust bin using the ultrasonic sensor. Once the waste gets to the pre-set level, the microcontroller activates the GSM modem to send a message to a designated number. The status of the waste in the bin is transferred to the designated line and display on the LCD whenever it exceeds the pre-set value. The replacement of the traditional waste bin with smart waste bin help in efficient management of waste by assuring that filled waste bin are emptied when the pre-set value is exceeded. This also help in reducing time involve in checking the status of the waste bin and number of trips embarked by the waste collection vehicle and total expenditure associated with collection is minimized. It eventually helps to maintain cleanliness in our environment. Therefore, the system makes the waste collection more efficient.
\end{abstract}

\section{INTRODUCTION}

Recently, the population rise and the significant increase in human activities cum production and consumption pattern has result to increase in generation of waste. Management of solid waste is a requirement in achieving a developed nation status, the nexus between effective solid waste management system, healthy environment, and quality living is very important. In many cities of the world, waste bins placed in public places are filled beyond their capacity and these portend ineffectiveness [1]. Effective solid waste management is one of the requirements in achieving the status of a developed nation. In the coming decade, foreign investment attraction to a nation will largely be influenced by healthy and clean environment, more so, a large percentage of the world's population will be residing in the cities. These aids development of smart cities perceptions geared towards decent urban living utilising innovative know-hows [2]. Management of solid waste is a vital process in any nation, it cut across every facets of the country for example standard of living, economy, healthcare, education, and pattern of living. Effective management of solid waste aims at minimising the adverse effects on the above-mentioned areas. Due to the rapid population growth, a large portion of the generated waste are dumped by the roadsides and water bodies, thereby causing environmental hazards. Waste collection and segregation has been a great challenge to effective waste management due to lack of legal framework that link to management of waste which includes regulations on waste recycling [3]. The current global technological advancement, industrial revolution, and urbanization call for sustainable development policies and plans. Huge investment has been made by several nations of the world towards the establishment of smart cities. The present waste management schemes are not sufficing to control the significant increasing waste level. The conventional waste management practices, where cleaners are charged with the responsibilities to empty the waste bins at a specified period of the day, this approach has a lot of demerits [4]. Findings from numerous researches have shown that collection and transfer of solid waste mechanism provided for citizens takes over two-thirds budgetary provision in developing nations and less than two-thirds in developed nations for example unclassified waste pose a challenge to reduce, reuse and recovery which will ultimately require human personnel for sorting out waste into various categories. This diminishes the budgetary allocation and decreases the resources to be expended on other aspect of waste management such as recycling of waste. Also, ineffective, and inefficient collection techniques result to detrimental and unsavoury conditions that constitutes environmental hazards to the immediate communities. These perils can be in form of spill-over waste bins and foul smell, these overfilled waste bins serve as breeding place for mosquitoes and other insects, thus increasing the spread of diseases $[5,6]$. 


\section{LITERATURE REVIEW}

Ghorpade-Aher et al. [7] developed a system of two major components that are the waste bin and garbage collecting truck, on command when the bin is full; it acts like a robot. On the rim of the bin and at the base of the robot facing forward are ultrasonic sensors. As a microcontroller, a Raspberry Pi zero $\mathrm{W}$ was used, and waste level and weight were measured using sensors to verify that the waste bin did not overflow. The waste container follows a predetermined path to a specific location, where garbage collection trucks will empty its contents once it is full. A Smart Home dustbin with radio frequency identification (RFID) technology and a door opening mechanism is also envisaged [8]. It is positioned at a specific height above ground level, allowing for interaction between the trashcan and the home dustbin via RFID. When the waste reaches its maximum level, an ultrasonic sensor will alert you. When the moving trash (Binbot) is interfaced with, the door opening mechanism is activated, and the waste is disposed of. The Internet of Things IoT is implanted in the moving trashcan using ultrasonic sensor, infrared sensor, and RFID transmitter. The flying rubbish follows a predetermined path owing to a line following mechanism $[9,10]$.

A flame sensor, raspberry pi, ultrasonic sensor, load cell, humidity sensor, GSM module, Wi-Fi, and LCD were used to develop integrated garbage level monitoring system for the trashcan [11]. With the use of sensors and wireless communication capabilities, the suggested system ensures real-time monitoring of trash levels, hence boosting the waste management system's efficiency. Another technique presented by Tambekar et al. [12], is to utilise sensors and a GSM module to monitor garbage collection and disposal inefficiencies and anomalies. Ultrasonic sensors were installed at various fill levels in the bin, allowing the device to operate continuously even in harsh conditions. A text message was sent to the waste management authorities using the GSM module.

In Manikandan et al. [13], the proposed system form by using an IR sensor, rain sensor, gas sensor, and microcontroller. The bin interfaced with Microcontroller PIC16F877A based IR sensor, rain sensor, gas sensor. The IR sensor indicates the level of waste in the bi; the rain sensor is an electrical conductor when the water drops on the sensor. It passes current, and it senses. Then the lid will automatically close. The gas sensor detects foul gas and relates to the microcontroller. When the waste level reaches the pre-set value, the signal will be sent to the waste truck drivers for prompt action to be taken. Bhatt et al. [14] developed a useful model of an automatic dustbin for the eradication of overflow waste bin. This model was made using Arduino microcontroller integrated with an IR sensor and servo motor for the opening of the bin lid and ultrasonic sensors for detecting waste level by measuring distance based on the time taken between the transmission and the reception phase. Also, ESP8266 a Wi-Fi module that is completely loaded with the TCP/IP stack, thus allows the micro-controller to link to numerous Wi-Fi networks. It is capable of both hosting an offloading application from any microprocessor. However, fire outbreak and rainfall were not considered in the development of the model.

The "Smart Garbage Management System" is the title of this study. Jajoo et al. [6] presents an observational study of a garbage bin using an Arduino Uno R3 controller, an ultrasonic sensor, and a Wi-Fi Model ESP8266, which connects the
Arduino to a Wi-Fi network and allows the Arduino to send and receive alert signals. Only a single bin was implemented in this way. This solution, on the other hand, can be used for a number of bins, each with its own identity, while simultaneously including the IoT principle via SQL technology and a login portal for authorised individuals. Alsayaydeh et al. [15] created a smart dustbin that used an App to control a buzzer, LED, fan, Wi-Fi module, and ultrasonic sensors. When the ultrasonic sensor senses approaching items, the motor opens the lid. Blynk Apps will show the current waste level. When the amount of waste reaches a predetermined threshold, a reminder will be sent to the person in control, alerting them that the bin will soon be full. Once the bin reaches its maximum capacity, a notification will be issued via the Blynk Apps to empty the garbage bin, and a buzzer will sound. However, the system cannot message beyond the distance of $100 \mathrm{~m}$.

Raaju et al. [16] developed a smart waste bin which assesses the waste level status of the bin via a sensor network, an android application developed with necessary info related to the several levels of waste dustbins which is in different areas. Notifications are being sent to truck drivers once it is filled. This system is made possible with the help of ZigBee, with sensors and modules. Also, it is powered by a solar panel, which is renewable energy. However, the monitoring can be done using WANET, which more efficient than ZigBee. Also, due to coverage, the cost of each node can be decreased using alternatives techniques. Prakash and Jayalakshmi [17] developed a smart waste management system that was used as an outdoor testbed. The system includes meshwork and cycle characteristics that allow bin suppliers to assess whether a specific site need an extra bin to be placed nearby, or the removal or relocation of current bins, based on data obtained from the waste bin. This always makes it easier for the cleaning crews to plan ahead. It is, however, installed as an outdoor testbed, which restricts its use.

This paper discusses a smart means of handling garbage via IoT protocol for the transmission of waste bin status wirelessly and as well generate e-mail notification to the designated authority that the waste bin is filled and required to be swapped. This system utilizes the Ultrasonic sensor to show waste level, and proximity sensors detect objects in front of the bin. Also, LCD has been integrated to show the current situation of the bin. However, segregation of waste was not considered in this research work [18]. Siddique et al. [19] proposed a system whereby dustbins are incorporated with microcontroller built systems having an Ultrasonic sensor for detecting waste level and $\mathrm{Wi}-\mathrm{Fi}$ module to link to the internet. An Android application was developed to show the real-time status of the bin Also; shortest direction will be specified on the map. Furthermore, the waste amount sensing system was not taken into consideration.

Gaddam et al. [20] investigated a smart system for waste management via IoT that used an ultrasonic sensor to assess waste level and also used a Raspberry Pi for data processing. The Raspberry Pi's Wi-Fi module was used to relay sensor data to the cloud. Furthermore, whenever the garbage reaches a certain level, the App uses Google Maps to display the bin and its location. The current position of the truck driver is also displayed, as well as the shortest trip utilising GPS. However, the power supply limits the functionality of the system. In this paper, a device was developed, to help in the separation of metallic and non-metallic waste into different bins, two modules were developed one for separation of metallic 
material and the later module for real-time monitoring of waste bin to the waste management authority via an app which defines an efficient path and displays it to the user [21].

Teja et al. [22] developed a Keen dustbin employed the use ultrasonic sensors for garbage level monitoring and sending alerts to the client informing the status of the bin via a GSM modem. An LCD is incorporated to display the waste bin status per time. Also, a buzzer is added to the framework to beep whenever the level of trash received traverses the set limit. However, the weight of the waste collected and the collection time were not taken into account $[23,24]$. Using an Arduino board coupled to a Wi-Fi module and an ultrasonic sensor, Chattopadhyay et al. [25] developed a smart sensing system to every single bin within the campus area. When the bin is less than $5 \mathrm{~cm}$ unfilled, the sensor is oriented towards the face of the bin, and the bin condition is reported as full. A Website was also created to display the status bin; the state of the bin will be viewed on a regular basis and the sweepers will be notified accordingly.

Baihaqi et al. [26] investigated time management in waste collection in the city by the use of a smart bin in this study. Data from Padang City was used to simulate time and route. A solar panel, an infrared sensor for bin lid opening and shutting, a GSM module for delivering messages to the person in charge, and an ultrasonic sensor for detecting bin load are all included in the proposed smart bin. This paper describes a project that uses an IoT-based bin to track dustbins and complaint waste management systems. A mobile app was created to track the location of garbage cans and to detect overflowing trash in a specific residential neighbourhood. Complaints are sent to the authorities via this mobile app. The waste truck's response time, on the other hand, was not considered [27]. In this study, the authors developed a scalable technology for use in cities that can accomplish and implement fill level estimation of waste collected but with minimum power consumption utilizing cheap embedded components. Ultrasonic sensors are used for sensing, providing information that is deciphered for estimating waste fill-level based on extensive simulations in MATLAB and physical experiments. The core of this system lies in Radio Frequency Identification (RFID). Information retrieval and sensor control were achieved via RFID tags [28]. In this work, a low power consumption smart bin was developed by Utomo et al. [29] consist of small powered embedded components ranging from ultrasonic range finder for measuring of waste level, microcontroller. The power consumption of the device was minimised via a developed algorithm and network protocol. The developed system was implemented and evaluated to validate the system feasibility. Furthermore, based on the estimated results, the system has low power consumption characteristics, although the waste data collected fluctuates. Rajathi et al. [30] presented a robotic trashcan that moves along a lined path with the assistance of two infrared sensors at the robot's base looking forward. It has an obstacle sensor on the side that detects black and sounds a buzzer, signalling a standstill for a period of time for trash to be dumped. In addition, an ultrasonic sensor is installed on the bin's rim to detect the garbage level. The Wi-Fi module updates the web page with the state of the bin, showing whether it is full or empty. An Arduino integrated development environment loaded onto a microcontroller is used to programme the robotic bin.

\section{METHOD}

The system is in three modules, the first module which detects a person standing in front of waste bin, by an ultrasonic sensor triggering the servo motor the opening of the waste bin lid for waste to be deposited inside the bin, the lid remains open for 5 seconds after the detected objected has been removed. The top of the waste bin closes back till the ultrasonic sensor detects another object. Second, this module checks the waste level inside the bin; whether it is half-filled or filled by using an ultrasonic sensor, the sensor transmits sound waves when waste is deposited in the bin. Corresponding waves are received based on the object distance. The Arduino board has been programmed in a manner that when the bin is half-filled, messages will be sent to a designated GSM number. Simultaneously the status of the bin will be displayed on the LCD in a text format. The message will be sent, and the status also will be displayed when the waste bin is filled. Third, this module is designed in such a manner that odour/foul smell and smoke will be detected by an MQ2 gas sensor when an odour is detected, messages will be sent to the designated GSM line, and the LCD will display it. The schematic diagram of the flowchart for the system is depicted in Figure 1 while the Schematic diagram of the smart sensing system is presented in Figure 2.

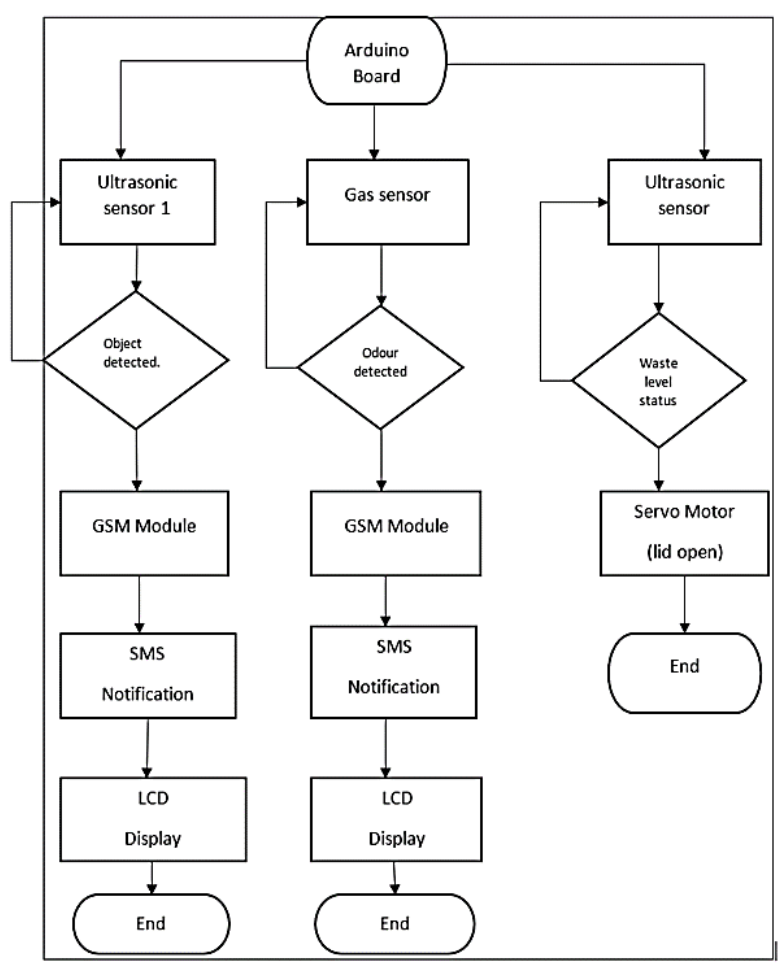

Figure 1. Flowchart of the system

\section{RESULT AND DISCUSSION}

The developed smart waste bin (see Figure 3) was tested for functionality of the various units and a framework was developed to evaluate its performance using three test cases using an adult, a teenager, and a child, varying the object distance between $12 \mathrm{~cm}$ and $3 \mathrm{~cm}$. Table 1 . Shows the servo time response. The comparative analysis of the time response result for a child, a teenager, and an adult is presented in Figure 4. 


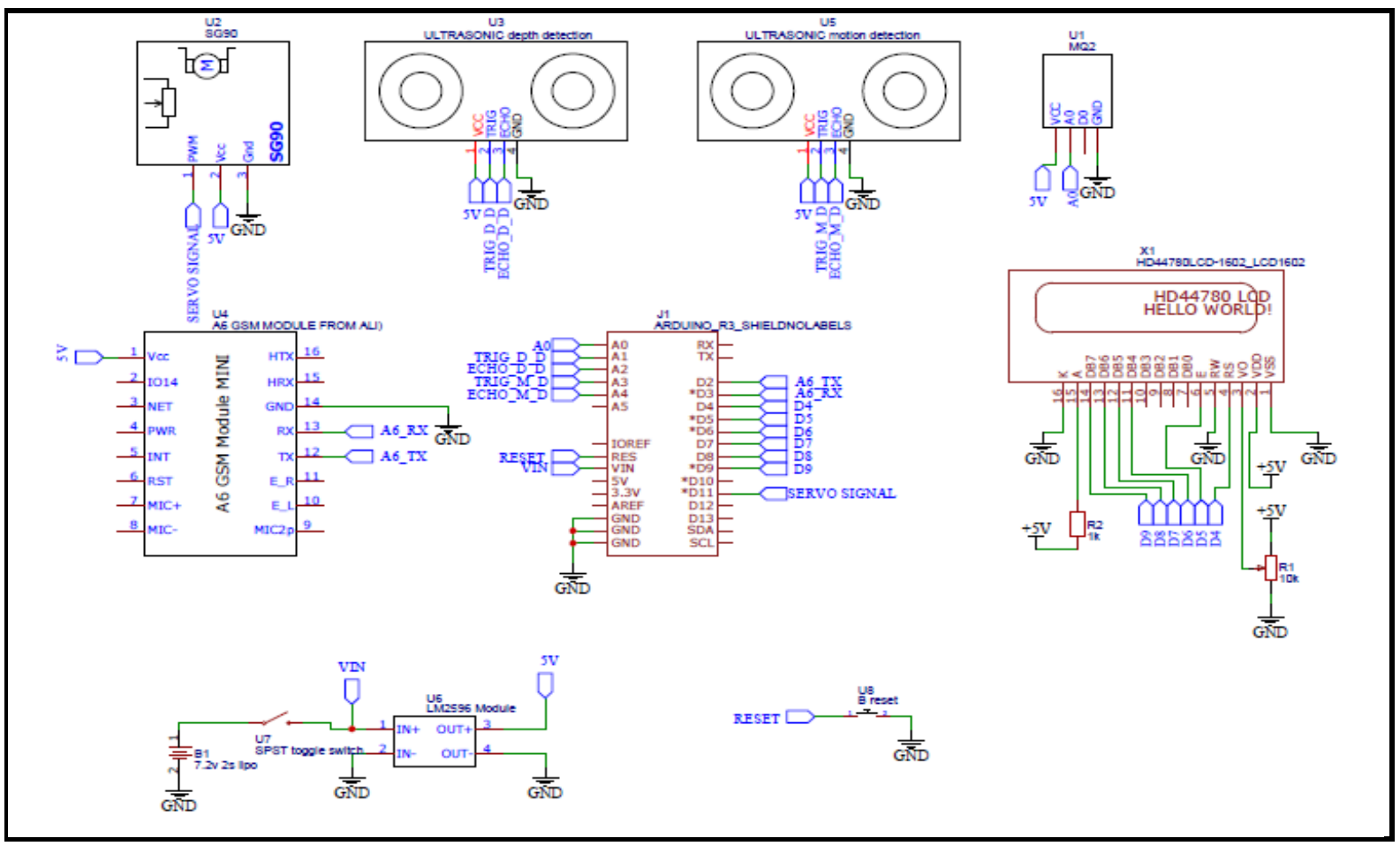

Figure 2. Schematic diagram of the smart sensing system

Table 1. Time response result

\begin{tabular}{cccc}
\hline Object Distance(cm) & Time Response(sec) & Time Response(sec) & Time Response(sec) \\
\hline & Child & Teenager & Adult \\
$\mathbf{1 2 . 5}$ & 30 & 40 & 45 \\
$\mathbf{1 5}$ & 45 & 60 & 0 \\
$\mathbf{2 0}$ & 0 & 0 & 0 \\
$\mathbf{2 5}$ & 0 & 0 & 0 \\
$\mathbf{3 0}$ & 0 & 0 & 0 \\
$\mathbf{3 5}$ & 0 & 0 & 0 \\
\hline
\end{tabular}

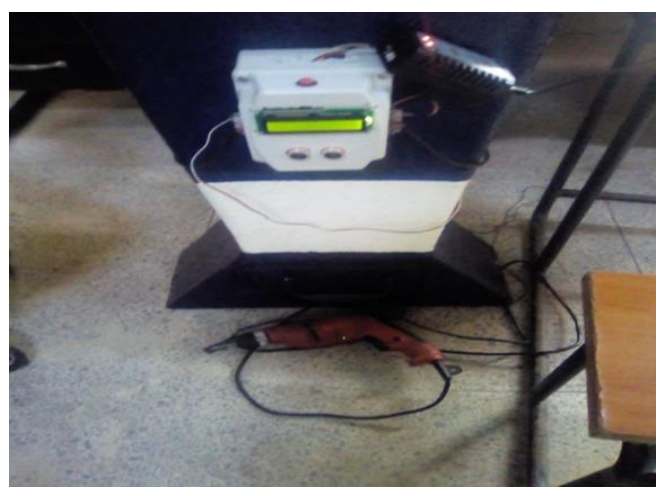

Figure 3. The developed smart waste bin

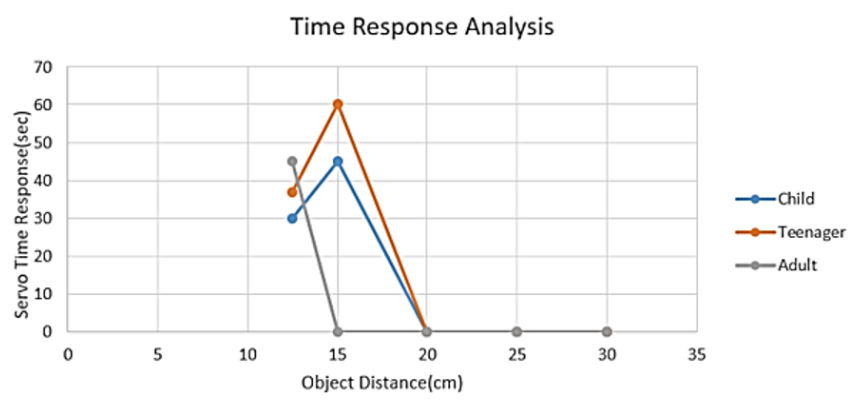

Figure 4. Comparative analysis of the time response result for a child, a teenager, and an adult

\subsection{Test for object detection and waste bin lid opening}

The smart waste bin in incorporated with an ultrasonic sensor for object detection at a range of $12.5 \mathrm{~cm}$, an object was placed in front of the sensor at a range above the pre-set value of $12.5 \mathrm{~cm}$. The waste bin lid did not open while the object was placed at $12.5 \mathrm{~cm}$, the sensor triggers the servo motor and the lid of the bin open as shown in Figure 5.

An ultrasonic sensor is fitted to the lid of the developed smart waste bin facing downward, it has two pins (trigger and echo). the trigger transmits the sound wave towards the bottom of the smart waste bin while the echo receives the sound wave. The waste level status is being monitored, the status is being displayed via the LCD, "The smart waste bin is half-filled", also at the pre-set maximum value. It was displayed on the LCD" The smart waste bin is filled".
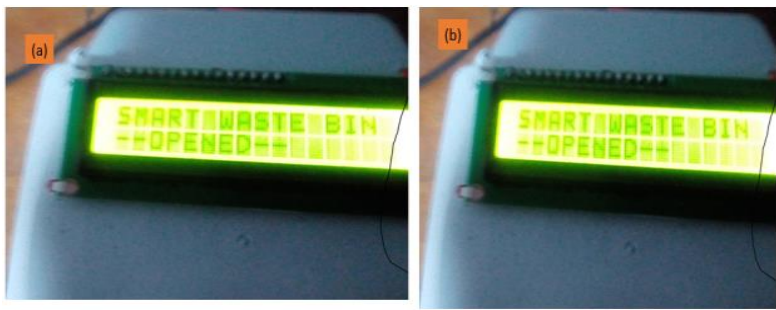

Figure 5. (a) Waste bin lid open test (b) Waste level detection test 


\subsection{Test for SMS}

Through the GSM module integrated with the smart waste bin and registered subscriber identity module (SIM). When the smart waste bin level is detected both at the half-filled/filled level messages were sent to a designated GSM line. Also, when an odour was detected in the bin a message was sent to the designated GSM number. This indicates that the GSM module is functional as indicated in Figure 6.

The MQ2 gas sensor fitted inside the smart waste bin is able to detect alcohol, smoke, methane and carbon dioxide. Since, $80 \%$ of gases produced from landfill are methane and carbon dioxide. It was tested by igniting a lighter to produce carbon dioxide, and it was detected. A message was displayed on the LCD "Odour detected" as indicated in Figure 7.

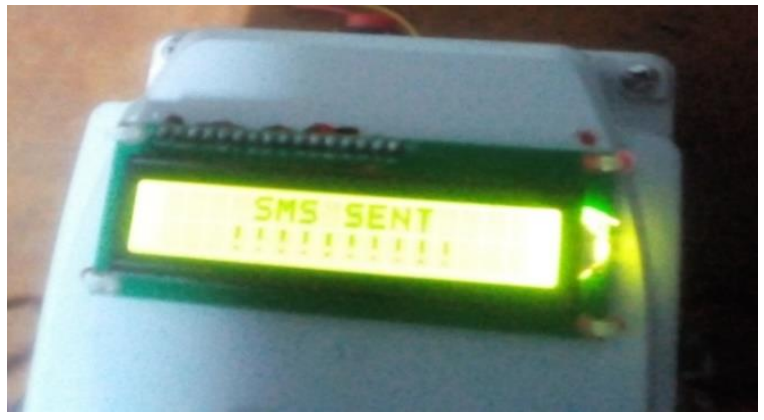

Figure 6. SMS test

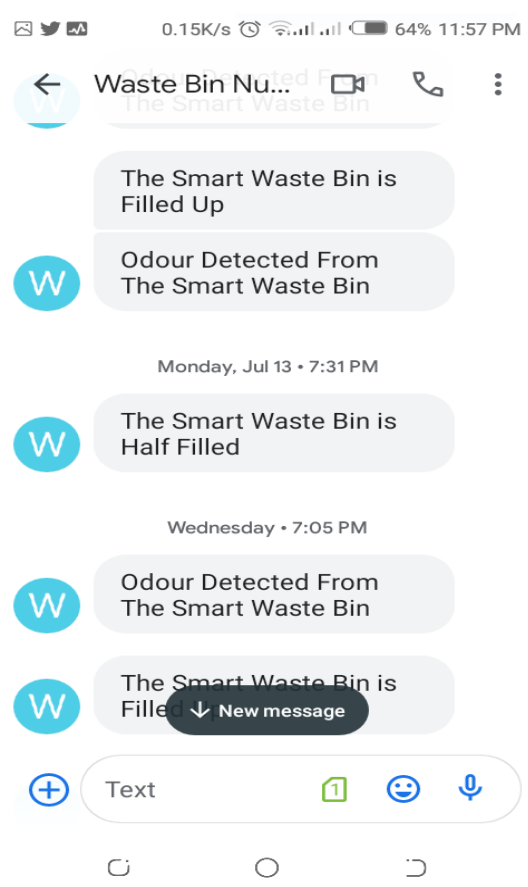

Figure 7. SMS Notification

\section{CONCLUSION}

This paper aimed at developing an optimize waste bin using smart sensing technology and evaluate the performance of the developed smart waste bin. This was achieved by utilising an Arduino board-based controller was integrated with ultrasonic sensors and gas sensor for the optimisation of the waste bin. The developed smart waste was evaluated with three test cases in other to determine the servo time. The optimised waste bin has a better servo time response for a child, and it is efficient and effective in monitoring waste. However, there is a need for further improvement. Future research work can be carried out to implement the following suggestions:

- A periodical replacement of the $7.4 \mathrm{~V}$ LIPO battery to prolong the system usage.

- A buzzer can be incorporated into the system to alert the user when a foul smell is detected.

\section{ACKNOWLEDGMENT}

We acknowledge the financial support offered by Afe Babalola University, Ado Ekiti in the actualization of this research work for publication.

\section{REFERENCES}

[1] Rajapandian, B., Madhanamohan, K., Tamilselvi, T., Prithiga, R. (2019). Smart dustbin. International Journal of Engineering and Advanced Technology (IJEAT), 8(6): 4790-4795. https://doi.org/10.35940/ijeat.F9359.088619

[2] Omar, M.F., Termizi, A.A.A., Zainal, D., Wahap, N.A., Ismail, N.M., Ahmad, N. (2016). Implementation of spatial smart waste management system in Malaysia. In IOP Conference Series: Earth and Environmental Science, 37: 012059. https://doi.org/10.1088/17551315/37/1/012059

[3] Gayanthika, W.A.L., Maduranga, G.K.C.D., Silva, A.I.S., Wikramarathne, S.D.H.S., Ranasinghe, R.M.I.S. (2019). Smart dustbin for waste management. International Journal of Environmental Science and Development, 10(4): 118-121. https://doi.org/10.18178/ijesd.2019.10.4.1159

[4] Radhika, V., Rukkumani, V., Devasena, D., Ramya, R. (2019). Smart waste management system using IoT. International Journal of Research in Arts and Science, 5: 65-72. https://doi.org/10.9756/bp2019.1001/08

[5] Muyunda, N., Ibrahim, M. (2017). Arduino-based smart garbage monitoring system: Analysis requirement and implementation. 2017 International Conference on Computer and Drone Applications (IConDA), Kuching, Malaysia pp. 28-32. https://doi.org/10.1109/ICONDA.2017.8270394

[6] Jajoo, P., Mishra, A., Mehta, S., Solvande, V. (2018). Smart garbage management system. 2018 International Conference on Smart City and Emerging Technology (ICSCET), Mumbai, India, pp. 1-6. https://doi.org/10.1109/ICSCET.2018.8537390

[7] Ghorpade-Aher, J., Wadkar, A., Kamble, J., Bagade, U., Pagare, V. (2018). Smart dustbin: An efficient garbage management approach for a healthy society. In 2018 International Conference on Information, Communication, Engineering and Technology (ICICET), Pune, India, pp. 1-4. https://doi.org/10.1109/ICICET.2018.8533851

[8] Sanukrishna, S.S., Prakash, M.J. (2018). Thermal and rheological characteristics of refrigerant compressor oil with alumina nanoparticles-an experimental investigation. Powder Technology, 339: 119-129. https://doi.org/10.1016/j.powtec.2018.08.003

[9] Purushothaman, R., Bharathi, V. (2018). Automatic bin bot- garbage collecting system in residential areas and 
enlightening disposal mechanism. International Research Journal of Engineering and Technology (IRJET), pp. 1312-1314.

[10] Masane, G.V., Naphade, R.A. (2017). Smart garbage monitoring system: Present and future. Int. J. Trend Sci. Res. Dev. (IJTSRD), 1(6): 26-31.

[11] Olorunsola, A.B., Ikumapayi, O.M., Oladapo, B.I., Alimi, A.O., Adeoye, A.O.M. (2021). Temporal variation of exposure from radio-frequency electromagnetic fields around mobile communication base stations. Scientific African, 12 : e00724 https://doi.org/10.1016/j.sciaf.201.e00724

[12] Tambekar, A., Channe, V., Raut, A., Chahodkar, A., Bhoskar, A., Thool, A. (2018). Innovation waste collection system using wireless sensor network AKA 'Smart Dustbin'. Innovation, 5(2): 1979-1980.

[13] Manikandan, R., Jamunadevi, S., Ajeyanthi, A., Divya, M., Keerthana, D. (2019). An analysis of garbage mechanism for smart cities. Int. Res. J. Eng. Technol, 6: 1709-1713.

[14] Bhatt, M.C., Sharma, D., Chauhan, A. (2019). Smart dustbin for efficient waste management. International Research Journal of Engineering and Technologi, 6(7): 967-969.

[15] Alsayaydeh, J., Wong, A., Khang, Y., Indra, W.A., Shkarupylo, V. (2019). Development of smart dustbin by using apps. Journal of Engineering and Applied Sciences, 14(21): 3703-3711.

[16] Raaju, V.A., Meeran, J.M., Sasidharan, M., Premkumar, K. (2019). IOT based smart garbage monitoring system using ZigBee. 2019 IEEE International Conference on System, Computation, Automation and Networking (ICSCAN), Pondicherry, India, pp. 1-7. https://doi.org/10.1109/ICSCAN.2019.8878742

[17] Prakash, S., Jayalakshmi, V. (2018). An efficient smart garbage dustbin monitoring system enhanced with wi-fi technology. International Journal of Pure and Applied Mathematics, 119(12): 6789-6795.

[18] Kolhatkar, C., Joshi, B., Choudhari, P., Bhuva, D. (2018). Smart e-dustbin. 2018 International Conference on Smart City and Emerging Technology (ICSCET), Mumbai, India, pp. 1-3. https://doi.org/10.1109/ICSCET.2018.8537245

[19] Siddique, M.J., Islam, M.A., Nur, F.N., Moon, N.N., Saifuzzaman, M. (2018). BREATHE SAFE: A smart garbage collection system for Dhaka city. In 2018 10th International Conference on Electrical and Computer Engineering (ICECE), Dhaka, Bangladesh, pp. 401-404. https://doi.org/10.1109/ICECE.2018.8636767

[20] Gaddam, M., Thatha, V.D., Kavuluri, S.R., Popuri, G.K. (2018). Smart garbage collection management system. Int. J. Eng. Technol., 7(2.7): 193-196. https://doi.org/10.14419/ijet.v7i2.7.10291

[21] Sharma, S., Chauhan, V., Jain, A. (2019). Smart and inexpensive implementation of garbage disposal system for smart cities. International Journal of Recent Technology and Engineering (IJRTE), 8(3): 3220-3224. https://doi.org/10.35940/ijrte.C5396.098319

[22] Teja, L.N., Bharathi, K., Krishna, P.G., Students, U.G., Pradesh, A., Pra-desh, A. (2018). Smart dustbin based on IOT. Int. J. Eng. Technol., 7(2.7): 348-351. https://doi.org/10.14419/ijet.v7i2.7.10713

[23] Frempong, V.E. (2013). Municipal solid waste management in Tarkwa area council (TAC), Ghana. International Journal of Sustainable Development and Planning, 8(4): 563-575. https://doi.org/10.2495/SDPV8-N4-563-575

[24] Joseph, F.G., Folorunsho, J.O., Yusuf, Y.O., Aruya, E.I. (2020). Assessment of solid waste management techniques in Maitama, Abuja, Nigeria. International Journal of Sustainable Development and Planning, 15(2): 227-233. https://doi.org/10.18280/ijsdp.150213

[25] Chattopadhyay, P., Chaudhuri, R., Dasgupta, S., Priya, G (2017). Smart garbage monitoring system school of computer science and engineering. Int. J. Eng. Res. Technol, 6(5): 705-710.

[26] Baihaqi, M.Y., Wijaya, W., Widyoko, M.A.R., Wikaningrum, T. (2018). The prospect of using smart dustbin for reducing garbage pick up time (A simulation in padang city). Journal of Environmental Engineering and Waste Management, 3(2): 61-67.

[27] Khan, A., kumar Agrawal, S. (2018). IoT based smart waste bin to track dustbin and public complaint management system. 2018 8th International Conference on Communication Systems and Network Technologies (CSNT), Bhopal, India, pp. 1-7. https://doi.org/10.1109/CSNT.2018.8820272

[28] Papalambrou, A., Karadimas, D., Gialelis, J., Voyiatzis, A.G. (2015). A versatile scalable smart waste-bin system based on resource-limited embedded devices. In 2015 IEEE 20th Conference on Emerging Technologies \& Factory Automation (ETFA), Luxembourg, Luxembourg, pp. 1-8. https://doi.org/10.1109/ETFA.2015.7301466

[29] Utomo, S.K.T., Hamada, T., Koshizuka, N. (2018). Lowenergy smart trash bin architecture for dynamic waste collection system. Proceedings of the 2nd International Conference on Future Networks and Distributed Systems, New York, United States, pp. 1-7. https://doi.org/10.1145/3231053.3231077

[30] Rajathi, G.I., Vedhapriyavadhana, R., Priya, L.R. (2019). Robotic dustbin on wheels. International Journal of Innovative Technology and Exploring Engineering (IJITEE), $\quad 9(1)$ : 1990-1993. https://doi.org/10.35940/ijitee.L3021.119119 